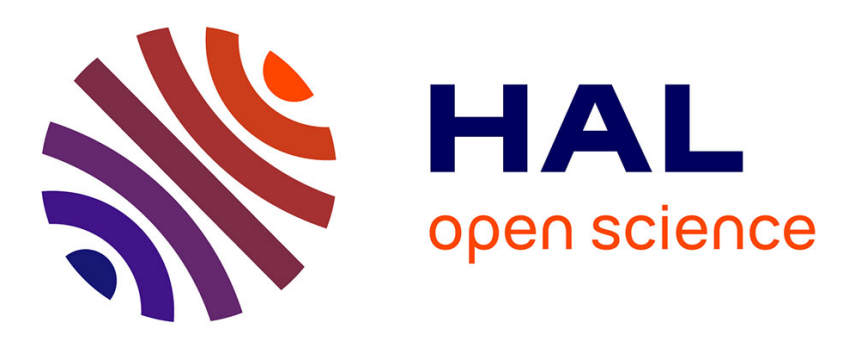

\title{
Assessing the efficiency of rural health centres in Burkina Faso: an application of Data Envelopment Analysis
}

Paul Marschall, Steffen Flessa

\section{- To cite this version:}

Paul Marschall, Steffen Flessa. Assessing the efficiency of rural health centres in Burkina Faso: an application of Data Envelopment Analysis. Journal of Public Health, 2008, 17 (2), pp.87-95. 10.1007/s10389-008-0225-6 . hal-00478186

\section{HAL Id: hal-00478186 https://hal.science/hal-00478186}

Submitted on 30 Apr 2010

HAL is a multi-disciplinary open access archive for the deposit and dissemination of scientific research documents, whether they are published or not. The documents may come from teaching and research institutions in France or abroad, or from public or private research centers.
L'archive ouverte pluridisciplinaire HAL, est destinée au dépôt et à la diffusion de documents scientifiques de niveau recherche, publiés ou non, émanant des établissements d'enseignement et de recherche français ou étrangers, des laboratoires publics ou privés. 


\title{
Assessing the efficiency of rural health centres in Burkina Faso: an application of Data Envelopment Analysis
}

\author{
Paul Marschall $\cdot$ Steffen Flessa
}

Received: 10 March 2008 / Accepted: 14 August 2008 / Published online: 16 September 2008

(C) Springer-Verlag 2008

\begin{abstract}
Background Effective health care provision benefits from the support of measurement techniques. Contrary to the situation in industrialised countries efficiency analyses in the health care sector in Africa are a very recent phenomenon. Hardly any of the existing studies was conducted at the level of primary care.

Aim The purpose of this study was twofold: (1) to evaluate the relative efficiency of health centres in rural Burkina Faso and (2) to investigate reasons for inefficient performance.

Methods Data Envelopment Analysis (DEA) was applied. To account for the situation in that country, the output-oriented approach was used in connection with different returns to scale assumptions. To identify the spatial effect of the catchment area on efficiency the Tobit model was applied.

Results According to constant returns to scale, 14 health centres were relatively efficient. The DEA projections suggest that the inefficient units were too big to be efficient. Tobit regression showed that the relatively efficient health centres are located close to villages in their catchment area. Conclusions For ethical reasons it is not appropriate to try to improve the efficiency of health centres by closing some of them. Their efficiency can be improved and lives can be saved if access to health centres is enhanced.
\end{abstract}

Keywords Burkina Faso · DEA · Efficiency · Nouna . Primary care

Funding: This study was supported by a research grant of the German Research Foundation (Deutsche Forschungsgemeinschaft).

P. Marschall $(\bowtie) \cdot$ S. Flessa

Faculty of Law and Economics, Department of Health Care

Management, University of Greifswald,

Friedrich-Loeffler-Str. 70,

17489 Greifswald, Germany

e-mail: paul.marschall@uni-greifswald.de

\section{Introduction}

Health care expenditures in most developed countries have grown dramatically in recent decades. It is widely believed that the inefficiency of health care institutions has, at least in part, contributed to this phenomenon. Less efficiency means a waste of resources which could have been used elsewhere where inputs were missing. Inadequate supply of health services can lead to early death. In response to this challenge a growing body of literature has emerged dealing with the efficiency of health care services in industrialised countries (Hollingsworth et al. 1999).

For a long time the discussion on improving efficiency hardly took account of less-developed countries. Financing health services in these countries was perceived as identifying possibilities to mobilise additional resources. Diminishing official development assistance in the 1990s, the discussion on the Millennium Development Goals and the resources to fulfil them induced reconsideration of the economics in running health facilities. The knowledge of the levels and determinants of health services' efficiency can help policy-makers and health care managers to avoid waste and to make most efficient use of scarce resources.

To measure efficiency and productivity several analytical methods were developed. Beside parametric methods, e.g. frontier analysis, Data Envelopment Analysis (DEA) has become a popular benchmarking tool for evaluating the efficiency of decision-making units (DMU). In a quite recent bibliography of DEA Tavares (2002) listed more than 3,200 papers, books, monographs, etc. addressing a great variety of problems written by more than 1,600 authors in 42 countries.

Initially, DEA was particularly applied in the non-profit sector, since measuring efficiency there is quite difficult. Studies were conducted to identify the efficiency of schools 
(Ray 1991), prisons (Butler and Johnson 1997) or public transport (Barnum et al. 2007). An important rationale for using DEA in the health sector is its applicability to the multiple input-output nature of health care provision and the simplicity of the assumptions underlying the method. Because of the increased financial pressure on public health systems and the availability of more appropriate databases, efficiency analyses were conducted in industrialised countries quite early as means to help reduce costs. By contrast, there are only a few applications of DEA in subSaharan Africa so far. As a consequence of insufficient data information systems not much is known about the efficiency of health care facilities. Most of the published studies about this topic focus on the hospital level, comparing the relative performance of facilities at the same health care level. Analyses at the hospital level were made for example in Botswana (Ramanathan et al. 2003), Namibia (Zere et al. 2006), South Africa (Kirigia et al. 2001) and Zambia (Masiye et al. 2002). Facilities at the level of primary care are still unstudied so far. Analyses focusing on the peripheral level were only conducted in Kenya (Kirigia et al. 2004), Sierra Leone (Renner et al. 2005) and in South Africa (Kirigia et al. 2001) studying even larger facilities than the ones in Burkina Faso, where hospitalisation is only provided in case of emergency.

In this paper we aim to provide information on the importance of efficiency measurement of health care facilities in developing countries. We state that efficiency measurement can be a substantial contribution to saving lives. Therefore we analyse the performance of health centres in rural Burkina Faso making use of data which were taken from a comprehensive long-term cost information system. In the subsequent parts of this article, the study site is described and the DEA method outlined. The ensuing analysis of the data is carried out in two stages. Firstly, quantitative aspects concerning relative efficiency are presented. Secondly, the measures of performance are explained. The implications of the results are then discussed.

\section{Methods}

Study site

The study was carried out in the research area of the Centre de Recherche en Santé de Nouna (CRSN), which is in the Nouna Health District in the province of Kossi, Northwestern Burkina Faso. This is a landlocked country in subSaharan Africa with an estimated population of about 13 million, $84.5 \%$ of which live in rural areas (Ministère de Santé 2006). The Kossi area is a dry savannah. Nearly 288,000 people live there, $300 \mathrm{~km}$ away from the capital
Ouagadougou (Ye et al. 2005). The population is extremely poor and the literacy rate is only $28.3 \%$ (Traore and Pale 2005). Most of them work as subsistence farmers, producing crops like millet and sorghum. The region is predominantly inhabited by the Dafing/Marka, Bwaba, Mossi and Peulh ethnic groups. There are three main religious groups: $65 \%$ Muslim, 29\% Christian and 6\% traditional religion. The most important diseases there (as \% of total burden of disease) are malaria (28\%), diarrhoeal diseases $(20 \%)$ and lower respiratory infections (12\%) (Würthwein et al. 2001). There is a seasonal pattern of morbidity. Most malaria cases occur during or briefly after the rainy season, which lasts from June until October. Most of the malaria burden is in children, with pre-school children experiencing at least six fever episodes and two malaria episodes per year (Kouyaté et al. 2007).

The province has, like most others in the country, an inadequate health delivery system compared to the urban areas. Formal health services in the Nouna Health District comprise a small hospital in Nouna town (Centre Medical avec Antenne Chirurgicale, CMA) and 25 local health centres (Centre de Santé et de Promotion Sociale, CSPS). Each CSPS provides basic outpatient services and includes a dispensary and maternity unit staffed by a certified nurse and a trained midwife. Linked to every CSPS public pharmacy services are provided. There are also vaccination programmes which are operated locally. The CMA, which is equipped with nearly 100 beds with surgical facilities, is the first referral level for the rural health centres.

\section{DEA}

The concept of efficiency is based on the ratio of output $y$ to input $x$ quantities of a production process. Consequently, producing a maximum of output out of a given amount of input, or alternatively realising a given output with minimum quantities of inputs, shows greatest success. According to this concept a firm, organisation or facility (DMU) is efficient if it operates on its corresponding production possibilities frontier. The efficiency of a multiple-output, multiple-input DMU $k$, with $k=1, \ldots, n$, can be presented as follows:

$\frac{\sum_{j} u_{j k} y_{j k}}{\sum_{i} v_{i k} x_{i k}}=\theta_{k}$,

where $u$ measures the weight of each output $y_{j}(j=1, \ldots, s)$ and $v$ indicates the weight of each input $x_{i}(i=1, \ldots, m)$. The idea of measuring efficiency as a relative distance from this frontier was originally developed by Farrell (1957). The efficient frontier of the group $(\theta=1)$ is constituted by the most efficient DMUs to which the efficiencies of the 
remaining DMUs are related. This implies that the efficiency score $\theta$ falls between 0 and 1 .

As soon as Charnes et al. (1978) introduced DEA in its present form, researchers from various fields quickly recognised its strengths for modelling operational processes for performance evaluations of homogeneous DMUs. Firstly, DEA is non-parametric, meaning that no functional form has to be assumed for the relationship between inputs and outputs. It uses linear programming to construct a piece-wise convex linear-segmented efficiency frontier, thus being much more flexible than econometric frontier analysis. Secondly, it is possible to include multiple inputs and outputs in DEA, which is especially important for the analysis of health care services, whereas the weights are calculated within the DEA procedure. The DEA method allows variable and fixed inputs, whereas the variable inputs might change in the short run while the values of the fixed inputs are only allowed to be changed in the long run. The DEA approach allows each DMU to choose the optimum weightings for the outputs $(u)$ and inputs $(v)$. Each DMU is considered in turn and its most favourable weights are selected. Special features provide the adjustment of the analysis to the concrete problem setting.

The efficiency score (1) can be transformed into a maximisation or a minimisation problem according to the orientation of a DMU manager to improve efficiency. The assumption of output-oriented DEA is that the outputs of the $k$ th DMU are expanded until the combination of inputs and outputs for this DMU reaches the production possibility frontier. As managers are sometimes faced with given quantities of feasible outputs they have to solve the corresponding input-oriented linear programming. Primal and dual formulations can be constructed. DMUs may operate with different returns to scale. The CCR model incorporates constant returns to scale in production. The output-oriented linear programming envelopment for the DMU under evaluation $k=0$ is:

$$
\begin{array}{ll}
\max _{\lambda_{0}} \theta_{0} & \\
\text { s.t. } & \sum_{k=1}^{n} \lambda_{k} x_{i k}-\theta_{0} x_{i 0} \geq 0, \\
& y_{j 0}-\sum_{k=1}^{n} \lambda_{j} y_{j k} \geq 0 . \\
& \lambda_{k} \geq 0 ;
\end{array}
$$

where the vector $\lambda$ represents intensity variables which indicate the necessary combination of efficient entities (reference unit or peer) for every inefficient DMU in order to form a "virtual unit" or benchmark that is on the frontier. Thus, $\lambda$ also represents the shadow prices related to the constraints limiting the efficiency of each unit to be no greater than 1. In DEA input excesses and output shortfalls are called slack. Input- and output-oriented approaches provide the same results under CCR. Banker et al. (1984) generalised the CCR formulation to allow variable returns to scale (VRS) (BCC model). CCR and BCC models differ only in the way that the latter includes convexity constraints. The usefulness of the scale assumption is to secure that any composite unit extrapolated is similar in size to the reference unit and not merely an extrapolation of another composite unit of a different size. Unlike CCR the BCC model allows for the consideration of fixed costs, which are not treated as inefficiencies.

In recent years a great variety of alternative DEA models was employed. However, CCR and BCC remain important cases for measuring efficiency, making the strongest and weakest assumptions, respectively. Based on the CCR and BCC scores, inefficiencies can be decomposed into their components. The output-oriented CCR model measures overall technical efficiency $\theta_{k}^{C C R}$ since it does not take the scale effect into account. The BCC model exclusively measures pure technical efficiency $\theta_{k}^{B C C}$. The ratio of the $\mathrm{CCR}$ and BCC efficiency measures will then yield an estimate of the pure scale efficiency (SE) of DMU $k$ (Banker et al. 1984), i.e.

$S E_{k}=\frac{\theta_{k}^{C C R}}{\theta_{k}^{B C C}}$,

indicating whether e.g. the different health centres were operating on an efficient scale in producing their services. The optimal size of a DMU is reached when a marginal increase of all inputs (scale) leads to the same relative increase of outputs. The bigger the difference between the scale efficiency score of a DMU and full scale efficiency $\left(S E_{k}=1\right)$, the more unfavourable are the consequences of scale. It tells us how much output of a DMU can be expanded until it is as efficient as the reference unit.

Many DEA applications adopt a two-stage methodology, in which regression analysis is used to explain the variation in "gross" efficiency scores generated by the first-stage DEA. The use of second-stage regression analysis serves two purposes. First of all, the drivers of gross efficiency can be identified. Secondly, "net" or "residual" efficiency scores can be computed from the residuals of the Tobit regression. Therefore, the DEA efficiency scores are transformed with the censoring point lying at zero:

$\tilde{\theta}_{k}=\left(1 / \theta_{k}\right)-1$,

The modified efficiency scores $\tilde{\theta}_{k}$ are used as dependent variables in standard Tobit regression. Some environmental factors may function as independent variables.

In order to capture variations in efficiency over the years, a technique called "window analysis" was proposed (Charnes et al. 1985). It assesses the performance of a DMU in the course of time by treating it as a different 
entity in each time performance. Thus, the capability of DEA was improved by measuring the performance of a unit or a process within a dynamical context.

Some important weaknesses of DEA have to be considered: There is no allowance for measurement error, omitted variable bias or randomness in estimating the frontier or the individual DMU's inefficiency. There exist demurs concerning the DEA's sensitivity to outliers and concerning its allowance for random shocks while determining efficiency. The DEA approach is also sensitive to an inappropriate ratio between the number of DMUs and variables. If the number of factors considered in the efficiency analysis is relatively high, the DEA approach may lead to substantial overestimates of the efficiency of DMUs (Banker et al. 1989).

\section{Data}

We used data collected by a comprehensive long-term cost information system, which was established in 2003 and covers both supply and demand sides and which contains information about direct and indirect costs. The provider information system gathers data from every health facility within the district. Both complementary information modules provide data that permit calculation of the total tangible costs of illness in the complete Health District. We used data from 20 CSPS from January to December 2004. Five CSPS were excluded. Three of them were constructed in 2004. As the CSPS Nouna moved to a new site data were also not available for the whole year. To avoid biases, one more health centre was dropped. Most of the people living in its catchment area belong to the conservative Islamic Wahabi movement who rejected some modern health care services such as the maternity ward until some staff members were replaced.

We also excluded data from the pharmacies because Burkina Faso joined the Bamako Initiative in 1992 and under this initiative pharmacies operate independently from the health centres they are linked to.
In order to measure CSPS efficiencies we restricted our analysis to four appropriate inputs and four important outputs. As inputs we chose (1) personnel costs in 2004 (US \$), (2) CSPS building area $\left(\mathrm{m}^{2}\right)$, (3) depreciation of CSPS equipment in 2004 (US \$) and (4) vaccination costs in 2004 (US \$). Personnel costs were used as a proxy for the production factor labour. The structure of the health care personnel across the health centres is quite similar concerning their qualification. In employment contracts for the public sector in Burkina Faso occupational skill and not working time determines individual earnings. Thus, personnel costs incorporate the qualification level. Most studies which assess efficiency in hospitals or bigger health facilities in developing countries use "number of beds" as an indicator for capital inputs. As hospitalisation in the CSPS occurs only in cases of emergency, beds are not appropriate indicators. Therefore, the building area of the CSPS buildings and the annual depreciation costs for equipment in the health centres were used. The lifetime of equipment was estimated using information from the Ministry of Health. Equipment with a value below 10,000 FCFA (US \$18.60) was depreciated at once. Vaccinating represents one of the most expensive activities which were performed at the level of primary health care. For carrying out this kind of prevention vaccines need to be defined as inputs (Marschall and Flessa 2008).

This study uses four output measures which indicate the main activities in the health centres: (1) general consultation and nursing care at the dispensary, (2) deliveries at the maternity ward, (3) immunisation and (4) special services, e.g. family planning, prenatal and postnatal consultations. All of these indicators are based on the number of cases; thus, they only reflect intermediate outputs.

Since the choice of a particular DEA model has effects on the study, the special situation in Nouna Health District has to be taken into account. The question of orientation deserves special attention. There are good reasons for choosing "input orientation" in industrial countries as there are no appropriate instruments for the management of health facilities to influence health care demand. However,

Table 1 Descriptive statistics of the input and output measures

\begin{tabular}{|c|c|c|c|c|}
\hline & Mean & Standard deviation & Minimum & Maximum \\
\hline \multicolumn{5}{|l|}{ Inputs } \\
\hline Personnel costs (US \$) & 5,868 & 3,526 & 1,670 & 20,550 \\
\hline Area $\left(\mathrm{m}^{2}\right)$ & 375 & 180 & 163 & 920 \\
\hline Equipment depreciation (US \$) & 4,888 & 2,169 & 1,498 & 10,748 \\
\hline Vaccine (US \$) & 10,845 & 5,655 & 5,085 & 29,028 \\
\hline \multicolumn{5}{|l|}{ Outputs } \\
\hline Number of general consultations & 3,735 & 1,835 & 1,359 & 6,980 \\
\hline Number of deliveries & 354 & 202 & 159 & 953 \\
\hline Number of other care & 2,661 & 1,186 & 768 & 5,029 \\
\hline Number of vaccinations & 4,860 & 2,513 & 1,834 & 11,385 \\
\hline
\end{tabular}


an "output-oriented" approach is appropriate for Nouna Health District. Local committees (Comité de Gestion, COGES), which are responsible for the administration of the health centres in Nouna Health District, have only limited control over the volume of inputs. Decision-makers at the level of the Health District and at the Ministry of Health take the relevant input decisions. They decide about the installation of a CSPS, provide primal endowment and pay the staffs' salaries. In theory, COGES can use local revenue from user fees to finance additional staff or new equipment, but in reality these resources are insufficient. There is a latent demand for health care services in lowincome countries. Many sick people seek traditional health care. A good quality of modern medicine might influence the local population in demanding biomedical health care (Baltussen et al. 2002). The CSPS staff has the duty to induce demand for preventive health care services such as family planning services, immunisations, etc. There exists also evidence that the perceived quality of health care at single health centres influences demand and thus output.

\section{Findings}

Table 1 presents the descriptive statistics of the input and output measures. According to official documents a CSPS is designed and staffed for about 10,000 patients, 1,000 deliveries and at least 5,000 preventive services per year. Nevertheless, the key input and output variables indicate a wide variation.

A more detailed analysis shows that the specific input and output data for most of the CSPS vary around the mean of the used input or output variable. The annual personnel costs of 12 CSPS vary between US $\$ 4,868$ and US $\$ 6,868$. However, the value of CSPS Djibasso differs notably. In this previous Centre medical (CM), which was downgraded in its status to a health centre, costs were $250 \%$ higher than the average. With the exception of vaccine costs, for which CSPS Dembo documented the highest factor input, the CSPS in Djibasso causes the highest costs. Among the output variables the number of nursing care and deliveries show the widest variability in relation to the average scores. While CSPS Bourasso dominates in the number of general consultation visits and other care, minimum outputs were realised by different CSPS facilities.

The assumption of constant returns to scale (CCR) is used as a starting point to evaluate relative efficiency under different scenarios. Table 2 presents the results.

The first column lists the locations of the analysed CSPS. According to the efficiency scores in the second column, 14 of the 20 CSPS under evaluation are best performers. Bagala turned out to be the health centre with the lowest performance $(\theta=0.4596)$. According to the CCR model Dembo is nearly efficient $(\theta=0.9907)$. The other two columns include the corresponding reference units for the inefficient DMUs and the $\lambda$ values, which are the raw weights assigned to peer units when solving the DEA optimisation problem. The higher the contribution, the closer in performance is the peer to the unit under consideration. The table shows that e.g. Barani, Berma and Bomborokuy are efficient $($ score=1). Bagala can virtually become efficient by combining the CSPS in Koro, Barani and Bourasso as peers, with raw weights of $\lambda=$ $0.3323, \lambda=0.1523$ and $\lambda=0.2335$, respectively. CSPS Koro is the peer unit with the highest $\lambda$ value in the reference set and thus the most comparable unit.

Follow-up analyses were conducted to analyse whether inefficient DMUs under CCR are more efficient under less stringent assumptions. It turned out that CSPS Bagala, which proved to be very inefficient under CCR, operated

Table 2 Efficiency scores and reference sets according CCR assumption

\begin{tabular}{|c|c|c|c|}
\hline DMU & Score & Reference set & $\lambda$ \\
\hline \multirow[t]{3}{*}{ Bagala } & \multirow[t]{3}{*}{0.4596} & Koro & 0.3323 \\
\hline & & Barani & 0.1523 \\
\hline & & Bourasso & 0.2535 \\
\hline Barani & 1 & & \\
\hline Berma & 1 & & \\
\hline Bomborokuy & 1 & & \\
\hline Borekuy & 1 & & \\
\hline Bourasso & 1 & & \\
\hline \multirow[t]{5}{*}{ Dara } & \multirow[t]{5}{*}{0.9245} & Koro & 0.1603 \\
\hline & & Bomborokuy & 0.0001 \\
\hline & & Nian & 0.3721 \\
\hline & & Bourasso & 0.1843 \\
\hline & & Konkuy Koro & 0.5180 \\
\hline \multirow[t]{4}{*}{ Dembo } & \multirow[t]{4}{*}{0.9907} & Koro & 0.2274 \\
\hline & & Nian & 0.2124 \\
\hline & & Berma & 0.2907 \\
\hline & & Barani & 0.3007 \\
\hline Djibasso & 1 & & \\
\hline Dokuy & 1 & & \\
\hline \multirow[t]{3}{*}{ Doumbala } & \multirow[t]{3}{*}{0.5850} & Djibasso & 0.0635 \\
\hline & & Nian & 0.6051 \\
\hline & & Bourasso & 0.2932 \\
\hline \multirow[t]{3}{*}{ Kienekuy } & \multirow[t]{3}{*}{0.6864} & Djibasso & 0.0001 \\
\hline & & Nian & 0.7105 \\
\hline & & Bourasso & 0.1955 \\
\hline Konankoira & 1 & & \\
\hline Konkuy Koro & 1 & & \\
\hline Koro & 1 & & \\
\hline Lekuy & 1 & & \\
\hline Nian & 1 & & \\
\hline \multirow[t]{3}{*}{ Sono } & \multirow[t]{3}{*}{0.6133} & Koro & 0.0001 \\
\hline & & Kononkoira & 0.0001 \\
\hline & & Nian & 0.6653 \\
\hline Toni & 1 & & \\
\hline Werebe & 1 & & \\
\hline
\end{tabular}


under increasing returns to scale (IRS). With regard to the other DMUs no change in efficiency could be diagnosed.

Table 3 presents the efficiency results for the remaining five inefficient CSPS under VRS, the most flexible returns to scale assumption. According to that model changes in inputs lead to disproportionate changes in outputs. The efficiency scores of the CSPS are listed next to the names. The fourth column shows DMUs' original input/output data. The projection column presents the results of the DEA calculations. A DMU is VRS efficient if it has no input excesses and no output shortfalls. Thus, the difference between original data and projection is $0.00 \%$. The improvements needed to reach the frontier are listed for each input/output.

The projections suggest that particularly the analysed CSPS are too big to be efficient. The results demonstrate e. g. that the efficiency of Dara can be improved if the input values of the personnel costs (area) are reduced by $14.54 \%$ $(16.28 \%)$. Similarly, efficiency can be attained if the output values of general consultation, deliveries, other care and vaccination are increased by 5.43, 74.4, 5.43 and $5.43 \%$, respectively. Based on the efficiency scores of the CCR and BCC analyses, scale efficiencies can be calculated. They are presented in Table 4:

Table 3 Efficiency scores, input-output original data and projection for inefficient CSPS according to the VRS assumption

\begin{tabular}{|c|c|c|c|c|c|}
\hline DMU & Score & Input/output & Original data & Projection & Difference $(\%)$ \\
\hline \multirow[t]{8}{*}{ Dara } & \multirow[t]{8}{*}{0.9485} & Personnel costs & 6,570 & 5,614 & -14.54 \\
\hline & & Area & 400 & 335 & -16.28 \\
\hline & & Equipment & 4,507 & 4,507 & 0.00 \\
\hline & & Vaccine & 10,153 & 10,153 & 0.00 \\
\hline & & General cons. & 4,453 & 4,695 & 5.43 \\
\hline & & Deliveries & 301 & 525 & 74.40 \\
\hline & & Other & 3,824 & 4,032 & 5.43 \\
\hline & & Vaccination & 5,156 & 5,436 & 5.43 \\
\hline \multirow[t]{8}{*}{ Dembo } & \multirow[t]{8}{*}{0.9946} & Personnel costs & 5,269 & 5,269 & 0.00 \\
\hline & & Area & 435 & 360 & -17.32 \\
\hline & & Equipment & 4,954 & 4,954 & 0.00 \\
\hline & & Vaccine & 29,028 & 13,360 & -53.98 \\
\hline & & General cons. & 4,844 & 4,870 & 0.55 \\
\hline & & Deliveries & 420 & 694 & 65.26 \\
\hline & & Other & 3,735 & 3,755 & 0.55 \\
\hline & & Vaccination & 6,987 & 7,025 & 0.55 \\
\hline \multirow[t]{8}{*}{ Doumbala } & \multirow[t]{8}{*}{0.5910} & Personnel costs & 6,119 & 6,119 & 0.00 \\
\hline & & Area & 562 & 388 & -30.94 \\
\hline & & Equipment & 6,008 & 5,057 & -15.83 \\
\hline & & Vaccine & 8,545 & 8,545 & 0.00 \\
\hline & & General cons. & 1,962 & 5,810 & 196.13 \\
\hline & & Deliveries & 214 & 433 & 102.55 \\
\hline & & Other & 1,989 & 3,365 & 69.20 \\
\hline & & Vaccination & 3,358 & 5,682 & 69.20 \\
\hline \multirow[t]{8}{*}{ Kienekuy } & \multirow[t]{8}{*}{0.6929} & Personnel costs & 5,961 & 5,961 & 0.00 \\
\hline & & Area & 432 & 403 & -6.78 \\
\hline & & Equipment & 4,913 & 4,864 & -1.02 \\
\hline & & Vaccine & 8,804 & 8,804 & 0.00 \\
\hline & & General cons. & 3,373 & 5,718 & 69.53 \\
\hline & & Deliveries & 251 & 470 & 87.24 \\
\hline & & Other & 2,186 & 3,155 & 44.31 \\
\hline & & Vaccination & 4,118 & 5,943 & 44.31 \\
\hline \multirow[t]{8}{*}{ Sono } & \multirow[t]{8}{*}{0.6588} & Personnel costs & 4,483 & 4,483 & 0.00 \\
\hline & & Area & 417 & 340 & -18.51 \\
\hline & & Equipment & 3,213 & 3,213 & 0.00 \\
\hline & & Vaccine & 7,923 & 7,923 & 0.00 \\
\hline & & Genral cons. & 2,268 & 3,991 & 75.96 \\
\hline & & Deliveries & 159 & 392 & 146.38 \\
\hline & & Other & 1,451 & 2,227 & 53.48 \\
\hline & & Vaccination & 3,063 & 4,649 & 51.79 \\
\hline
\end{tabular}


Table 4 Scale efficiency scores

\begin{tabular}{ll}
\hline CSPS & Scale efficiency \\
\hline Bagala & 0.4596 \\
Barani & 1 \\
Berma & 1 \\
Bokekuy & 1 \\
Bomborokuy & 1 \\
Bourasso & 1 \\
Dara & 0.9747 \\
Dembo & 0.9961 \\
Djibasso & 1 \\
Dokuy & 1 \\
Doumbala & 0.9898 \\
Kienekuy & 0.9906 \\
Konankoira & 1 \\
Konkuy Koro & 1 \\
Koro & 1 \\
Lekuy & 1 \\
Nian & 1 \\
Sono & 0.9310 \\
Toni & 1 \\
Werebere & 1 \\
\hline
\end{tabular}

In the case of the CSPS in Bagala this means that it operates locally efficiently (pure technical efficiency=1) whereas its overall technical inefficiency is caused by its failure to achieve scale efficiency, represented by $\mathrm{SE}=$ 0.4596. The scale efficiency of the DMUs Barani and Berma is 1 , i.e. they operate at the most productive scale size. Their technical efficiency is also 1 so they are both scale and technically efficient in both the CCR and BCC models.

Having measured the relative efficiencies it is also of considerable interest to explain different efficiency scores by investigating the determinants of technical efficiency. It is a common practice to employ Tobit regression or other methods to second-stage DEA in order to estimate this relationship (Hoff 2007). Since ownership and government regulations do not differ between the CSPS, location characteristics might explain differences in relative efficiencies. Socioeconomic and cultural data which might explain some of the exogenously determined inefficiencies were not available for the whole Health District. We tried to examine the influence of the health centres' spatial spreading on their performance. Data about the bidirectional distances between the $n$ villages and their nearest health centres $\left(d_{v}\right)$ and their population $\left(\right.$ pop $\left._{v}\right)$, respectively, were used to calculate distance measures for each CSPS $\left(D M_{k}\right)$. The $D M U_{k}$ were standardised by the total population within the catchment area of CSPS $k\left(P O P_{k}\right)$ :

$D M U_{k}=\frac{\sum_{v=1}^{n} d_{v} \cdot p o p_{v}}{P O P_{k}}$,
With the countryside being quite flat, the distance measure (5) indicates the spatial disadvantages of health centres compared to each other in $\mathrm{km}$. The values are presented in Table 5:

There is a wide variation in distances between the favoured CSPS Konkuy Koro $(7.2857 \mathrm{~km})$ and Doumbala $(95.7369 \mathrm{~km})$, with an average of $21.7605 \mathrm{~km}$. Relatively efficient health centres are located close to villages in their catchment area. Unlike that, it is not possible to give an interpretation regarding inefficient CSPS. In order to find out if an unfavourable location might be associated with bad performance, we conducted the Tobit regression with $D M$ as a single independent variable. While the model as a whole seems to be statistically significant ( $P$ value: 0.041 , McFadden's pseudo- $\left.R^{2}=0.910\right)$, the results for $D M$ are less sound ( $t$-test: 1.989, $P$ value: 0.061). However, the coefficient proves what we predicted that a more favourable location leads to a better performance. Overall the regression provides some evidence that some important variables might be missing. This means that there are other environmental variables that might influence the performance of the CSPS.

\section{Discussion}

The application of DEA demonstrates that many of the CSPS operated relatively efficiently. According to CRS 30\% of health centres in Nouna Health District were found to be inefficient, which is quite lower than the results obtained in

Table 5 Spatial disadvantage of health centres by distance measure

\begin{tabular}{ll}
\hline CSPS & Distance measure \\
\hline Bagala & 9.7806 \\
Barani & 30.1881 \\
Berma & 14.2116 \\
Bomborokuy & 8.6526 \\
Borekuy & 10.8076 \\
Bourasso & 17.2000 \\
Dara & 11.0887 \\
Dembo & 14.3864 \\
Djibasso & 29.8751 \\
Dokuy & 34.8277 \\
Doumbala & 95.7369 \\
Kienekuy & 14.1201 \\
Konankoira & 20.2743 \\
Konkuy Koro & 7.2857 \\
Koro & 20.4860 \\
Lekuy & 36.9226 \\
Nian & 12.9577 \\
Sono & 12.3855 \\
Toni & 12.5237 \\
Werebere & 21.5000 \\
\hline
\end{tabular}


Kenya (56\%) (Kirigia et al. 2004), Sierra Leone (59\%) (Renner et al. 2005) and in South Africa (70\%) (Kirigia et al. 2001). The difference might be explained by a rather homogeneous structure of the health centres in Kossi which were included in the analysis, excluding malfunctioning health facilities. However, the slack provides important information about the underlying waste of resources at the current level of actual demand. Scarce resources should be used in those parts of the health system where they provide the best return and thus save lives. Reallocating available resources is therefore often recommended (Evans et al. 2001). However, in the case of a low-income country the implications of an institutional reform at a concrete level within the health pyramid deserve some special attention, especially the following response of very poor households regarding the provision of these health services. The differences between original data and projection are mainly due to capital costs. As they are not variable they cannot be easily adjusted to actual demand. Since the health centres are located at the level of primary care they should be enhanced with appropriate capacities. In many CSPS the norms of the Ministry of Health regarding the required quantity of equipment which define an operating health centre are not reached. Downsizing of health facilities, which is recommended by other studies at the hospital level, would mean their closure. This in turn could mean that the total demand for health care might decrease, as the willingness to seek modern health care might be reduced because of larger distances to the next CSPS. In the case of malaria this might have fatal consequences: due to bad roads, the villages are often isolated during the rainy season. There is no alternative biomedical supply in the rural area of Kossi. Sick people might choose no care at all or traditional health care. From a traditional point of view malaria is often not regarded as a disease at all, but as a natural appearance during the course of the year. The concrete treatment behaviour is based on the local definitions of health problems occurring in the community as to whether they are due to natural causes, spirits or bewitchment.

Decreasing the number of health centres in connection with a simultaneous spatial reallocation of the remaining ones is also a purely theoretical solution neglecting high expenditures of the very poor households and future demand as a consequence of a growing population. Therefore, the only reasonable solution for managers can be strengthening efforts to increase the utilisation of biomedical health care. In order to become efficient, the six inefficient health centres as a whole have to increase their current output levels by $58 \%$ on average regarding general consultation, $79 \%$ regarding deliveries, $29 \%$ regarding other care and $28 \%$ regarding immunisation visits. This result is qualitatively in line with the studies on subSaharan Africa mentioned above.
The implementation of the recommendations derived from DEA is an important first step addressing the problem of a quite low level of efficiency that was analysed elsewhere (Marschall and Flessa 2008). The result of a technical efficiency score of $91 \%$ on average in the relative sense does not necessarily correspond with a high absolute efficiency. It is a common phenomenon that many health facilities in Africa do not operate at full capacity (Haddad et al. 2006). In spite of a low utilisation of biomedical health care (Mugisha et al. 2004) there is a high latent demand for health services in Nouna Health District. This problem is also reflected in the results of a recent study showing that the average governmental expenditures on health are less efficient in Africa than health spending in Asia and the Western Hemisphere (Gupta and Verhoeven 2001). In times of pressure on the health system, governments of wealthier countries tend to exclude less efficient health services from public financing. Donor countries and organisations frequently support health facilities in less developed countries on humanitarian grounds, e.g. for reaching the Millennium Development Goals. In a nutshell: solving the trade-off between efficiency and ethical considerations means first of all to increase the demand for modern health care. Shutting down facilities shall only be done when a more efficient health care facility is nearby.

\section{Conclusion}

The study applied DEA to evaluate the relative efficiency of 20 health centres in rural Burkina Faso. As the real production functions of the CSPS are unknown comparisons between them can be used as a tool to improve their performance. Apparently some of them are not used to its full capacity for the existing demand. This accurately illustrates the persisting dilemma. Downsizing and shutting down inefficient facilities seems to be apparent. According to DEA, small input adjustments can improve relative efficiency. However, cuts in supply are not appropriate since they could induce decreasing health care demand. In this respect efficiency can only be improved if more people are treated, which is also a declared goal of the health policy of Burkina Faso.

However, there might be some shortcomings in our analysis.

To measure the CSPS' efficiency we only used quantitative input and output variables. Of course qualitative variables also influence the efficiency of services. In Nouna Health District some empirical evidence is found that the perceived quality of care often differed between the health centres. As the satisfaction of patients influences the demand for services, current status and development of the routine health care quality in the Nouna Health District 
has been both a policy and a research issue for 25 years (Sauerborn 2005). There is some evidence that the quality of primary care has improved during that period. Unfortunately, such data are not available for the complete Health District and DEA is very sensitive concerning missing data (Banker et al. 1984).

We tried to apply the multi-stage DEA procedure, which is common in countries with well-developed data information systems. Having measured the relative efficiencies at the first stage it is also of considerable interest to explain different efficiency scores by investigating the determinants of technical efficiency. It was only possible to link the spatial distribution of the health centres with the efficiency of the facilities. Moreover, external factors might explain insufficient efficiency. Even though Nouna and its surroundings are a well-known research area, important socioeconomic and ethnological data for the whole Health District are not available.

It is also very important to analyse the performance of the different CSPS over a longer period of time. Because of incomplete provider data for 2003 it was not possible to use them for DEA analysis. If the data of subsequent years are available, it will be possible to evaluate the efficiency of the health centres within a dynamical context.

Acknowledgements The authors would like to thank Ali Sié, Bocar Kouyate, Maurice Yé, Mamadou Mariko and Dimitri Poda for their support during the data collection.

Conflict of interest The authors confirm that there are no relevant associations that might pose a conflict of interest.

\section{References}

Baltussen R, Yé Y, Haddad S, Sauerborn RS (2002) Perceived quality of care of primary health care services in Burkina Faso. Health Policy Plan 17:42-48

Banker RD, Charnes A, Cooper WW (1984) Some models for estimating technical and scale efficiencies in data envelopment analysis. Manage Sci 30:1078-1092

Banker RD, Charnes A, Cooper WW, Swarts J, Thomas D (1989) An introduction to data envelopment analysis with some of its models and their uses. In: Chan JL, Patton JM (eds) Research in governmental and nonprofit accounting. JAI Press, Greenwich, pp 125-163

Barnum DT, McNeil S, Hart J (2007) Comparing the efficiency of public transportation subunits using data envelopment analysis. $\mathrm{J}$ Public Transp 10:1-16

Butler TW, Johnson WW (1997) Efficiency evaluation of Michigan prisons using data envelopment analysis. Crim Justice Rev 22:1-15

Charnes A, Clark T, Cooper WW, Golany B (1985) A development study of data envelopment analysis in measuring the efficiency of maintenance units in U.S. Air Forces. Ann Oper Res 2:95-112

Charnes A, Cooper WW, Rhodes E (1978) Measuring efficiency of decision making units. Eur J Oper Res 2:429-444

Evans DB, Tandon A, Murray CJ, Lauer JA (2001) Comparative efficiency of national health systems: cross national econometric analysis. BMJ 323:307-310
Farrell MJ (1957) The measurement of productive efficiency. J R Stat Soc Ser A (General) 120:254-281

Gupta S, Verhoeven M (2001) The efficiency of government expenditure experiences from Africa. J Policy Model 23:433467

Haddad S, Nougtara A, Fournier P (2006) Learning from health system reforms: lessons from Burkina Faso. Trop Med Int Health 11:1889-1897

Hoff A (2007) Second stage DEA: comparison of approaches for modelling the DEA score. Eur J Oper Res 181:425-435

Hollingsworth B, Dawson P, Maniadakis N (1999) Efficiency measurement of health care: a review of non-parametric methods and applications. Health Care Manag Sci 2:161-172

Kirigia JM, Emrouznejad A, Sambo LG, Munguti N, Liambila W (2004) Using data envelopment analysis to measure the technical efficiency of public health centers in Kenya. J Med Syst 28:155166

Kirigia JM, Sambo LG, Scheel H (2001) Technical efficiency of public clinics in Kwazulu- Natal Province of South Africa. East Afr Med J 78(3 Suppl):S1-S13

Kouyaté B, Sie A, Yé M, De Allegri M, Müller O (2007) The great failure of malaria control in Africa: a district perspective from Burkina Faso. PLoS Med 4(6):e127. doi:10.1371/journal. pmed.0040127

Marschall P, Flessa S (2008) Expanding access to primary care without additional budgets? A case study from Burkina Faso. Eur J Health Econ. doi:10.1007/s10198-007-0095-9

Masiye F, Ndulo M, Roos P, Odegaard KA (2002) A comparative analysis of hospitals in Zambia: a pilot study on efficiency measurement and monitoring. In: Seshamani V, Mwikisa CN, Odegaard K (eds) Zambias Health Reforms Selected Papers 1995-2000. IHE, Lund, pp 473-481

Ministère de la Santé (2006) Annuaire statistique/ santé 2005. Ouagadougou

Mugisha F, Kouyate B, Dong H, Chepng'eno G, Sauerborn R (2004) The two faces of enhancing utilization of health-care services: determinants of patient initiation and retention in rural Burkina Faso. Bull World Health Organ 82:572-579

Ramanathan TV, Chandra KS, Thupeng WM (2003) A comparison of the technical efficiencies of health districts and hospitals in Botswana. Dev South Afr 20:307-320

Ray SC (1991) Resource-use efficiency in public schools: a study of Connecticut data. Management Science 37:1620-1628

Renner A, Kirigia JM, Zere EA (2005) Technical efficiency of peripheral health units in Pujehun district of Sierra Leone: a DEA application. BMC Health Serv Res 5:77. doi:10.1186/14726963-5-77

Sauerborn R (2005) Improving the quality of routine health services in the Nouna district through an iterative process of policy and research over the past 25 years. Ruprecht-Karls-Universität Heidelberg, Heidelberg

Traore C, Pale A (2005) Health inequalities in the rural district of Nouna, Bukrina Faso. Indepth health equality project. Indepth Working Paper Series No.3: Accra

Tavares G (2002) A bibliography of data envelopment analysis (1978-2001). Rutgers University, Rutcor Research Report, Piscataway

Würthwein R, Gbangou A, Sauerborn R, Schmidt C (2001) Measuring the local burden of disease. A study of years of life lost in subSaharan Africa. Int J Epidemiol 30:501-508

Ye M, Sié A, Millogo O (2005) Manuel de procedures du Centre Médical avec Antenne Chirurgical de Nouna. Nouna

Zere E, Mybeeli T, Shangula K, Mandlhate C, Mutirua K, Tjivambi B, Kapenambili W (2006) Technical efficiency of district hospitals: evidence from Namibia using data envelopment analysis. Cost Eff Resour Alloc 4:5. doi:10.1186/1478-7547-4-5 